\title{
Temporal variability of damage potential on roads as a conceptual contribution towards a short-term avalanche risk simulation
}

\author{
A. Zischg ${ }^{1,2}$, S. Fuchs ${ }^{3}$, M. Keiler ${ }^{4}$, and J. Stötter ${ }^{2}$ \\ ${ }^{1}$ Geo Information Management, Gargazzone, Italy \\ ${ }^{2}$ Institute of Geography, University of Innsbruck, Austria \\ 3 alpS Centre for Natural Hazard Management, Innsbruck, Austria \\ ${ }^{4}$ Department of Geography and Regional Research, University of Vienna, Austria
}

Received: 27 September 2004 - Revised: 3 February 2005 - Accepted: 21 February 2005 - Published: 23 February 2005

Part of Special Issue "Multidisciplinary approaches in natural hazard and risk assessment"

\begin{abstract}
The fatality risk caused by avalanches on road networks can be analysed using a long-term approach, resulting in a mean value of risk, and with emphasis on shortterm fluctuations due to the temporal variability of both, the hazard potential and the damage potential. In this study, the approach for analysing the long-term fatality risk has been adapted by modelling the highly variable short-term risk. The emphasis was on the temporal variability of the damage potential and the related risk peaks. For defined hazard scenarios resulting from classified amounts of snow accumulation, the fatality risk was calculated by modelling the hazard potential and observing the traffic volume. The avalanche occurrence probability was calculated using a statistical relationship between new snow height and observed avalanche releases. The number of persons at risk was determined from the recorded traffic density. The method resulted in a value for the fatality risk within the observed time frame for the studied road segment. The long-term fatality risk due to snow avalanches as well as the short-term fatality risk was compared to the average fatality risk due to traffic accidents. The application of the method had shown that the long-term avalanche risk is lower than the fatality risk due to traffic accidents. The analyses of short-term avalanche-induced fatality risk provided risk peaks that were 50 times higher than the statistical accident risk. Apart from situations with high hazard level and high traffic density, risk peaks result from both, a high hazard level combined with a low traffic density and a high traffic density combined with a low hazard level. This provided evidence for the importance of the temporal variability of the damage potential for risk simulations on road networks. The assumed dependence of the risk calculation on the sum of precipitation within three days is a simplified model. Thus, further research is needed for an improved de-
\end{abstract}

Correspondence to: A. Zischg

(a.zischg@geo-im.com) termination of the diurnal avalanche probability. Nevertheless, the presented approach may contribute as a conceptual step towards a risk-based decision-making in risk management.

\section{Introduction}

Snow avalanches pose a threat to settlements, infrastructure and road networks in alpine environments. To reduce this susceptibility to avalanche hazards, a considerable amount of money has been spent by the public sector to realise technical mitigation measures, particularly since the mid- $20^{\text {th }}$ century. As a result, the major avalanche starting zones are equipped with protection measures, such as snow supporting structures. Additionally, most of the endangered alpine road network is protected by avalanche galleries or is permanently or temporarily closed during the winter months. As a result of the increasingly limited financial resources of the public sector, there is a need for an efficient and sustainable policy of public expenditures for protection against natural hazards, especially for the protection of road networks, since they can only be reliably protected at high cost. Consequently, the costs and benefits of avalanche defence structures will be increasingly determined to allow for a comparison of different mitigation strategies and the related cost-effectiveness (Fuchs and McAlpin, 2005 ${ }^{1}$ ). Furthermore, there is a need for the combination of active, passive, and organisational measures resulting from the coping strategies against natural hazards on a regional level (Bründl et al., 2004) as well as on a superior level (UN/ISDR, 2004), leading to an enhancement regarding early warning systems.

\footnotetext{
${ }^{1}$ Fuchs, S. and McAlpin, M. C.: The net benefit of public expenditures on avalanche defence structures in the municipality of Davos, Switzerland, Nat. Haz. Earth Sys. Sci., accepted, 2005.
} 


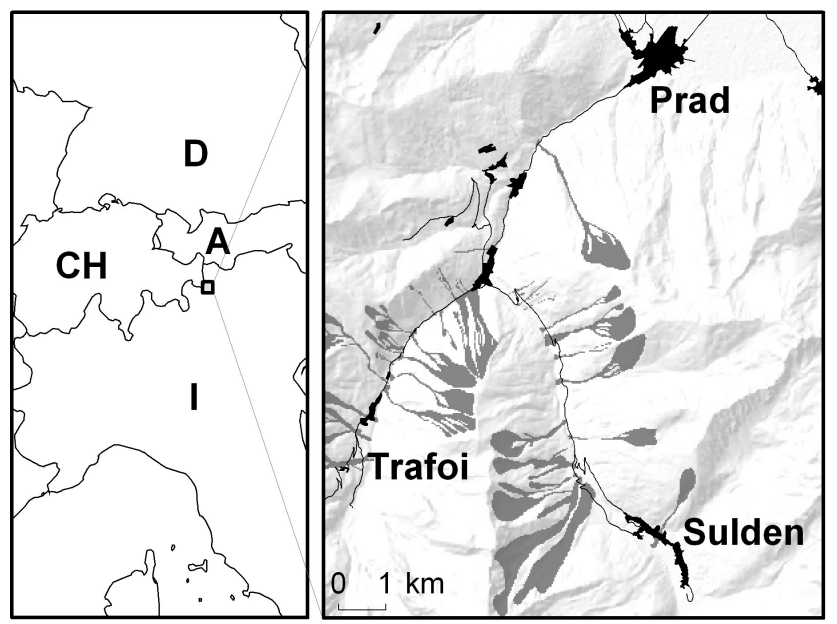

Fig. 1. Study area Sulden Road, Ortles Alps, South Tyrol, Italy.

The basic requirement for studies related to the costeffectiveness of protection measures and to the combination of different protection strategies is determined by the level of risk, particularly regarding the spatial as well as temporal variability of damage potential. However, there have been only few recently published studies focussing on this variability pertaining to alpine settlements (Keiler, 2004; Fuchs et al., 2004; Fuchs and Bründl, 2005). The temporal variability of damage potential on road networks and the resulting risk is still neglected. This study contributes to close this gap.

The damage potential on road networks is defined by the traffic density and is subsequently derived from the number of potentially endangered persons, as outlined in Wilhelm (1997). The daily traffic density, and, as a consequence, the resulting risk, is subject to considerable variations, particularly in regions affected by tourism. Apart from a situation with high hazard level and high traffic density, risk peaks result from both, a high hazard level combined with a low traffic density and a high traffic density combined with a low hazard level. The risk level can be considered for a long-term with regard to the live-span of permanent mitigation measures. Additionally, the level of risk can be studied for a short-term, regarding e.g. organisational measures like road closures. Therefore, the method for analysing risk for a long-term, as outlined in Wilhelm (1997), has to be adapted for the short-term set of calculations. Methodologically, this requirement can be met by a short-term risk simulation, as outlined in this study.

The method was developed and tested in the avalancheprone study area of the Sulden road between the municipalities of Prad and Sulden, Sulden Valley, Autonomous Province of Bozen, Italy (Fig. 1). This road serves as access road to the main ski area of the region and is therefore of particular importance for winter tourism. The road segment is $20 \mathrm{~km}$ long and branches at the "Karner bridge", five kilometres outside Sulden. The so-called "summer road" leads past the "Marlt" debris cone on the orographic left side of the
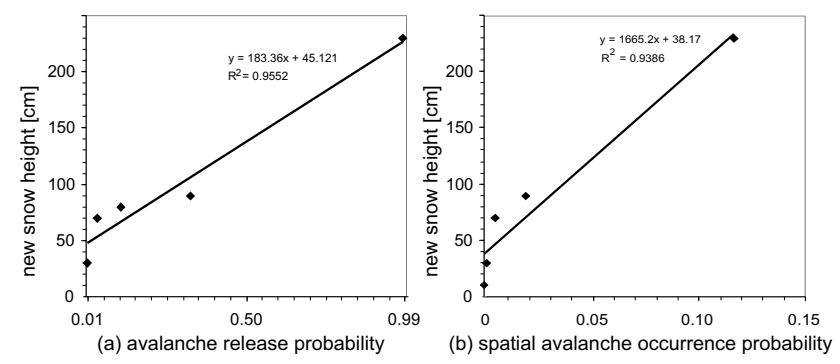

Fig. 2. Probability distributions of three-day precipitation at the Sulden road causing avalanches (modified from Zischg and Stötter 2004). (a) The ratio between the number of days with an observed avalanche event that hit the Sulden road and the total number of days in the observation period with the same classified amount of new snow is described. (b) The ratio between the number of diurnal avalanche events that hit the Sulden road and the total number of avalanche paths crossing the road section is presented, related to the classified amount of new snow.

Sulden Valley. The "winter road", which was built due to the considerable avalanche exposure of the "summer road" in the "Marlt" debris cone area, follows the orographic right side of the Sulden Valley. The "summer road" has been endangered by 22 avalanche paths which reached the road at least once during the 25 years of observation by the avalanche incident registry of the Autonomous Province of Bozen-South Tyrol. Due to the construction of permanent protection measures during the 1970s and 1980s, 17 avalanches on twelve paths remained perilous and threatened the road in 2004 (Fig. 1).

\section{Method}

Quantitatively, risk is defined as a function of the probability of occurrence of a hazard process and the expected height of damage, the latter being a product of the damage potential and the corresponding vulnerability (e.g. Varnes, 1984). This risk equation has initially been applied to the risk resulting from snow avalanches affecting roads by Wilhelm (1997, 1999). To obtain complete information on the risk situation, both, variations in the probability of occurrence and variations in the damage potential have to be taken into account. So far, there has been a methodological lack in the determination of the temporal variability of damage potential, as shown by Keiler et al. (2005) for alpine settlements. The required methodological procedures used in this study are described in the following sections, focusing on road networks.

\subsection{Analysis of long-term avalanche risk}

An analysis of the collective risk according to the methods presented in Wilhelm (1997), Borter (1999) and Margreth et al. (2003) was carried out, resulting in a value for the long-term development of risk. The emphasis of the study was on damage to persons. Tangible damage, such as loss of material assets, damage to road infrastructure and recovery costs has not been taken into account. The fatal- 
Table 1. Overview of the values used in the set of calculations of the long-term risk. Regarding the probability of death in vehicles $(\lambda)$, a value of 0.18 was chosen for those avalanche paths where a damaged car remains on the road after an incident, and a value of 0.40 was chosen for avalanche paths where a damaged car could be dislocated downwards the slope after an incident.

\begin{tabular}{crrrrrr}
\hline Avalanche path no. & $T$ (yrs.) & $g(\mathrm{~km})$ & $v(\mathrm{~km} / \mathrm{h})$ & $\lambda(1)$ & $\begin{array}{c}W D T \\
\text { (cars/day) }\end{array}$ & $\beta$ (pers./car) \\
\hline 84076 & 9.00 & 0.275 & 60 & 0.18 & 1300 & 2 \\
84070 & 27.00 & 0.020 & 50 & 0.40 & 951 & 2 \\
84069 & 27.00 & 0.055 & 60 & 0.40 & 951 & 2 \\
84068 & 2.08 & 0.125 & 30 & 0.40 & 951 & 2 \\
84067 & 27.00 & 0.060 & 50 & 0.18 & 951 & 2 \\
84066 & 13.50 & 0.015 & 40 & 0.18 & 951 & 2 \\
84063 & 13.50 & 0.030 & 50 & 0.18 & 951 & 2 \\
84039 & 13.50 & 0.100 & 50 & 0.18 & 951 & 2 \\
84040 & 13.50 & 0.050 & 55 & 0.18 & 951 & 2 \\
84042 & 27.00 & 0.080 & 50 & 0.18 & 951 & 2 \\
84043 & 27.00 & 0.080 & 50 & 0.18 & 951 & 2 \\
84044 & 6.75 & 0.035 & 30 & 0.40 & 951 & 2 \\
84045 & 13.50 & 0.125 & 30 & 0.40 & 951 & 2 \\
84046 & 27.00 & 0.125 & 30 & 0.40 & 951 & 2 \\
84047 & 27.00 & 0.400 & 35 & 0.40 & 951 & 2 \\
84048 & 27.00 & 0.300 & 60 & 0.18 & 951 & 2 \\
84061 & 300.00 & 0.060 & 50 & 0.18 & 951 & 2 \\
\hline
\end{tabular}

ity risk on roads was defined as a product of the probability of occurrence of an avalanche event and the corresponding extent of damage. The number of potential fatalities was derived from the average daily traffic during the winter months, the mean number of passengers per car, the speed of the vehicles crossing the avalanche paths, the mean widths of the avalanche paths, and the probability of death in vehicles resulting from accidents caused by avalanches (Wilhelm, 1997). The risk calculated for every single avalanche path was summed up to the collective risk for the whole road section (see Eq. 1; Wilhelm, 1997). The return period $(T)$ of every avalanche was empirically estimated using data from the avalanche incident inventory (Autonome Provinz Bozen-Südtirol/Lawinenwarndienst, 2003). The average traffic volume $(W D T)$ was calculated using statistics provided by the road traffic authorities (Autonome Provinz Bozen-Südtirol/ASTAT 2002, 2004). The mean width of the avalanche crossing the road $(g)$, the average speed of cars $(v)$ and the average number of passengers per $\operatorname{car}(\beta)$ were estimated on the basis of field studies. The probability of death in vehicles $(\lambda)$ caused by an avalanche incident was estimated following the suggestions in Wilhelm (1999) in combination with field studies. An overview of the applied values used for the set of calculation is given in Table 1. Related to the long-term system conditions, the computed values represent the mean risk resulting from avalanches in the studied road section.

$R_{0}=\frac{W D T \cdot \beta}{24 h} \sum_{i=1}^{n} \frac{g_{i}}{T_{i} \cdot v_{i}} \cdot \lambda_{i}$

$i=1,2 \ldots n$ avalanche paths.

\subsection{Analysis of short-term avalanche risk}

For calculating the effective short-term risk, Eq. (1) was modified, replacing the avalanche occurrence probability per year by the diurnal occurrence probability. This probability was deduced from the amount of new snow within three days, based on assessments of the statistical avalanche occurrence within the studied road section and analyses of precipitation data (Zischg and Stötter, 2004). The closest meteorological station is situated in Sulden but (a) the available data shows measurement gaps between 1938 and 1948 and between 1977 and 1987 and (b) water equivalents and not the amount of new snow are recorded. Therefore, observation data from the snow measuring station in Weissbrunn $(1900 \mathrm{~m}$ a.s.1.), $20 \mathrm{~km}$ south-east of the study area, was used. Since December 1983, snow heights, the amount of new snow and the snow temperature according to the guidelines of the Interregional Association for Snow and Avalanches in Italy AINEVA were measured at this station (Autonome Provinz Bozen-Südtirol/Lawinenwarndienst, 1983, 1997). The recorded maximum of new snow depth was $140 \mathrm{~cm}$ within one day and $234 \mathrm{~cm}$ within three days. The recorded snowfall events were compared with the avalanche observation database. For those avalanches that hit the road section, the amount of new snow accumulation within three days was analysed and classified in decimetre steps. For every classified amount of new snow accumulation, the number of days with an observed avalanche event was compared with all days in the observation period showing the same amount of new snow accumulation within three days. This relationship was plotted in a scatter diagram (Fig. 2a). A statisti- 
Table 2. Input values for the risk parameters of Eq. (4) and the related standard deviations used in the Monte Carlo simulation. The standard deviations were estimated on the basis of the used input data and additional field studies.

\begin{tabular}{cccccc}
\hline Avalanche path no. & $g(\mathrm{~km})$ & $v(\mathrm{~km} / \mathrm{h})$ & $\lambda(1)$ & $\beta$ (pers./car) & $P_{\mathrm{av}}$ (1) \\
\hline 84076 & 0.275 & 60 & 0.18 & 2 & Eq. (2) \\
84069 & 0.055 & 60 & 0.40 & 2 & Eq. (2) \\
84068 & 0.125 & 30 & 0.40 & 2 & Eq. (2) \\
84067 & 0.060 & 50 & 0.18 & 2 & Eq. (2) \\
84066 & 0.015 & 40 & 0.18 & 2 & Eq. (2) \\
84063 & 0.030 & 50 & 0.18 & 2 & Eq. (2) \\
84061 & 0.100 & 50 & 0.18 & 2 & Eq. (2) \\
84040 & 0.050 & 55 & 0.18 & 2 & Eq. (2) \\
84044 & 0.035 & 30 & 0.40 & 2 & Eq. (2) \\
84046 & 0.125 & 30 & 0.40 & 2 & Eq. (2) \\
84047 & 0.400 & 35 & 0.40 & 2 & Eq. (2) \\
84048 & 0.300 & 60 & 0.18 & 2 & Eq. (2) \\
\hline
\end{tabular}

cal regression was deduced, resulting in a linear relationship between the new snow accumulation within three days and the avalanche release probability. This relation, described in Eq. (2), was used for the determination of the daily avalanche occurrence probability of every avalanche path $\left(P_{\mathrm{av}}\right)$. Considering that not every snow fall event simultaneously triggers all avalanches on the studied road section, a distribution function of the spatial occurrence probability $\left(P_{\mathrm{sp}}\right)$ was calculated, using the same method as described for Eq. (2). In Fig. 2b, the ratio between the number of the observed diurnal avalanche events that hit the Sulden road and the total number of avalanche paths crossing the road section is shown, resulting in Eq. (3).

$$
\begin{aligned}
& P_{\mathrm{av}}=\frac{(N S-45.121)}{183.36} \\
& P_{\mathrm{sp}}=\frac{(N S-38.174)}{1665.2} .
\end{aligned}
$$

To calculate potential consequences of a given hazard potential, the number of persons at risk was estimated on the basis of the traffic volume ( $W D T$ ). Since 2002, automatic traffic counts for the Sulden road have been recorded on a daily resolution. As the road serves as main access road to the ski area of the region, the traffic density is significantly higher on weekends and during holidays (30\% above the average) than on weekdays (9\% below the average). The mean daily traffic density on the Sulden road is 951 vehicles per day (Autonome Provinz Bozen-Südtirol/ASTAT, 2002) and reaches a maximum of 2700 vehicles per day.

To calculate the short-term avalanche risk, variables determining the damage potential, such as the mean width of the avalanche crossing the road $(g)$, the average speed of cars $(v)$, the average number of passengers per $\operatorname{car}(\beta)$ and the probability of death in vehicles $(\lambda)$ were defined using the same method as in the long-term analysis of avalanche risk. The fatality risk for every individual avalanche path was calculated on the basis of the input parameters (a) new snow accumulation within three days $(N S)$ and (b) traffic density $(W D T)$. The calculated risk for every single avalanche path was subsequently summed up to the collective risk for the respective road section (Eq. 4). As a result, the fatality risk for the observed period (day) for different road segments was obtained.

$R_{\text {real-time }}=\frac{W D T \cdot \beta}{24 \mathrm{~h}} \cdot \sum_{i=1}^{n} \frac{g_{i}}{v_{i}} \cdot \lambda_{i} \cdot P_{\mathrm{av}} \cdot P_{\mathrm{sp}}$

$i=1,2 \ldots n$ avalanche paths.

The method was applied using data of the winter 2003/2004. For this period, the necessary input data was deduced from the traffic database (Autonome Provinz BozenSüdtirol/ASTAT, 2004) and the avalanche bulletins (mailing list of the Avalanche Warning Service, Autonomous Province of Bozen-South Tyrol, Italy). The stochastic uncertainty resulting from the data was analysed by means of a Monte Carlo simulation, as outlined in Zischg et al. (2004). The uncertainties of the input variables of Eq. (4) were described by their probability distributions, assuming a normal distribution. The probability distributions were calculated applying the mean values and the standard deviations presented in Table 2. The values of the standard deviations were retrieved on the basis of the described data and additional field studies. A sample of 1000 scenarios was created based on randomly generated values resulting from the probability distributions of every input parameter of Eq. (4). The collective fatality risk resulted from the mean of all computed scenarios. The standard deviation of the computed scenarios was used to specify the uncertainty in the result of the procedure.

\section{Results}

\subsection{Long-term fatality risk}

Based on Eq. (1) and the parameters presented in Table 1, the collective object risk was determined. For the Sulden road 


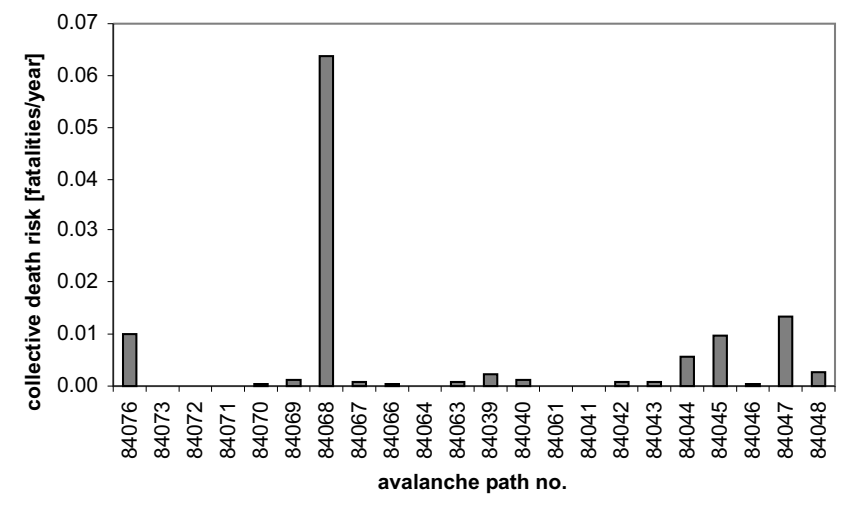

Fig. 3. Collective fatality risk presented for every avalanche path on the studied road section.

between the municipalities of Prad and Sulden, $7.98 \times 10^{-2}$ fatalities per year resulted for the "winter road" branch and $1.13 \times 10^{-1}$ fatalities per year for the "summer road" branch, which represented one fatality every 12.5 years compared to one fatality every 8.8 years. The individual fatality risk for a person using twice a day the "summer road" was $1.16 \times 10^{-4}$ per year. Comparing the collective object risk of the two road segments, a 1.4 times higher relative risk was observed for the Prad-Sulden connection via the "summer road" than for the Prad-Sulden connection via the "winter road". Comparing the two road segments, the collective object risk for the "summer road" was 11.7 times higher than for the "winter road". In Fig. 3, the calculated fatality risk is illustrated for every single avalanche path. The collective avalanche risk of the whole road section was mainly determined by the avalanche path no. 84068. For this avalanche path, a risk of $6.3 \times 10^{-2}$ fatalities per year was calculated. This avalanche path determined $56 \%$ of the collective object risk on the Sulden road, followed by the avalanche path no. 84047 with $1.3 \times 10^{-2}$ fatalities per year $(12 \%$ of the collective object risk).

\subsection{Short-term fatality risk}

Based on Eq. (4) and the parameters described in Table 2, the temporal variability of object risk was determined on the basis of the input parameters (a) sum of new snow height within three days and (b) observed daily traffic density. In Fig. 4, the results of the risk simulation on both road branches are presented for the winter 2003/2004. Risk peaks occurred on different avalanche hazard levels.

At the end of November 2003, the risk maximum was calculated with $2 \times 10^{-2}$ fatalities per day ( 28 November) and $3 \times 10^{-2}$ fatalities per day ( 29 November, see Table 3 ). On 28 November, the avalanche-associated fatality risk exceeded the statistical accident risk on the road $\left(6.7 \times 10^{-4}\right.$ fatalities per day; Zischg and Stötter, 2004) by a factor of 30. On 29 November, the avalanche-associated fatality risk was 50 times higher than the statistical accident risk on the road. The avalanche bulletin dated from 28 and 29 November 2003 cau- tioned about a threat to exposed traffic routes. Consequently, the road was closed during these days.

A second maximum occurred between 29 and 31 December 2003, ranging from $3 \times 10^{-4}$ to $1.6 \times 10^{-2}$ (Table 3 ). Thereby, the low avalanche hazard level, represented by the respective small new snow depth during the calculation procedure, was compensated by a higher traffic density. The avalanche-associated fatality risk on 31 December exceeded the statistical accident risk on the road by a factor of 20 .

A third maximum of calculated fatality risk occurred at the beginning of November 2003, the calculated fatality risk was $4 \times 10^{-3}$ fatalities per day (Table 3 ). On 3 November, the avalanche-associated fatality risk was six times higher than the statistical accident risk on the road. The third maximum resulted from a high avalanche hazard level, represented by the respective amount of new snow during the calculation procedure, combined with low traffic density.

The risk values described above were based on 1000 computed scenarios. The results of the Monte Carlo simulation indicated the statistical spread in the calculated risk values (see Table 3), the standard deviations ranged from $2.6 \times 10^{-3}$ to $2.2 \times 10^{-2}$ and the confidence intervals $(95 \%)$ ranged between $1.3 \times 10^{-5}$ and $1.3 \times 10^{-3}$ fatalities per day.

\section{Conclusions}

Considering the long-term timeframe, the results of risk analyses serve as a basis for designing and optimising protection measures, mostly based on cost-benefit-analyses (Wilhelm, 1999). Short-term risk analyses serve as a decision basis whether or not organisational measures, such as road closures, should be implemented. This decision basis is provided by means of short-term avalanche risk simulation. The risk is calculated starting with the analysis of hazard potential, taking into account the current environmental conditions and the estimated number of persons at risk on the basis of the effective traffic volume. In a further step, the quantitative value for the current fatality risk resulting from avalanche risk can be compared to the fatality risk resulting from traffic accidents in the study area. If the risk due to road accidents is assumed to be the level of accepted risk, this comparison may serve as a decision-making tool whether or not additional risk reducing measures have to be implemented.

The result of the long-term avalanche risk analysis suggested that the computed collective avalanche risk on the Sulden road via the "Marlt" debris cone was lower than the effective fatality risk in the past decades. Since the 1970s, 12 persons went lost on the Sulden road due to avalanches (Hurton, 1991; Martinelli, 1993; Autonome Provinz BozenSüdtirol/Lawinenwarndienst, 2003). This resulted in an effective fatality risk of 0.4 per year, which represents one fatality every 2.5 years, while the calculated fatality risk was 0.11 per year, representing one fatality every 8.8 years. This difference could be explained by the implementation of avalanche protection measures in the 1970s and 1980s, as well as the construction of the "winter road". 


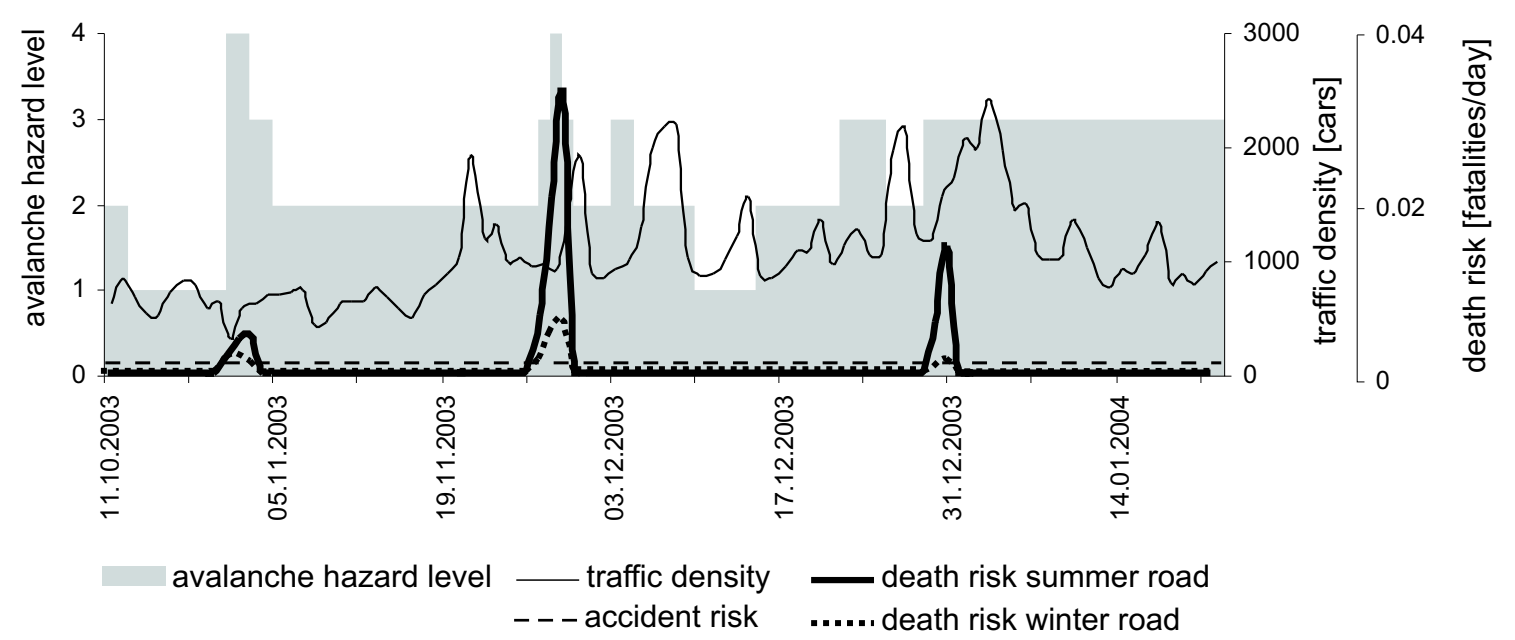

Fig. 4. Collective fatalitiy risk along the Sulden road from Prad to Sulden via "summer road" and via "winter road" - example for the situation between 1 November 2003 and 23 January 2004.

Table 3. Mean daily traffic, amount of new snow, fatalities per day, and associated uncertainties for the risk peaks shown in Fig. 4. The results are based on a Monte Carlo simulation with 1000 runs. Due to the uncertainties of the input parameters, the decimal places have to be rounded up for further processing.

\begin{tabular}{rrrccc}
\hline \multicolumn{1}{c}{ Date } & $\begin{array}{c}\text { WDT } \\
\text { (cars/day) }\end{array}$ & $\begin{array}{r}\text { amount of new } \\
\text { snow in 3D }(\mathrm{cm})\end{array}$ & $\begin{array}{c}\text { death risk summer } \\
\text { road (fatalities/day) }\end{array}$ & $\begin{array}{c}\text { standard } \\
\text { deviation }\end{array}$ & $\begin{array}{c}\text { confidence } \\
\text { interval }(95 \%)\end{array}$ \\
\hline 1 Nov. 2003 & 320 & 80.0 & 0.00256427 & 0.00275971 & 0.00017105 \\
2 Nov. 2003 & 584 & 80.0 & 0.00457342 & 0.00405496 & 0.00025132 \\
3 Nov. 2003 & 630 & 80.0 & 0.00484618 & 0.00345182 & 0.00021394 \\
26 Nov. 2003 & 957 & 50.0 & 0.00027994 & 0.00020730 & 0.00001284 \\
27 Nov. 2003 & 978 & 80.0 & 0.00745965 & 0.00507226 & 0.00031438 \\
28 Nov. 2003 & 933 & 110.0 & 0.02284919 & 0.01585536 & 0.00098271 \\
29 Nov. 2003 & 1491 & 110.0 & 0.03526824 & 0.02183860 & 0.00135354 \\
29 Dec. 2003 & 1240 & 50.0 & 0.00037254 & 0.00027075 & 0.00001678 \\
30 Dec. 2003 & 1176 & 70.0 & 0.00477409 & 0.00294007 & 0.00018222 \\
31 Dec. 2003 & 1574 & 85.0 & 0.01606564 & 0.01879707 & 0.00116503 \\
\hline
\end{tabular}

Compared to the calculated long-term collective fatality risk resulting from avalanches, the average fatality risk resulting from traffic accidents on the studied road section was significantly higher with $2.4 \times 10^{-1}$ fatalities per year (Autonome Provinz Bozen-Südtirol/ASTAT, 2003; Zischg and Stötter, 2004). The mean fatality risk due to a traffic accident at the "summer road" was about two times higher than the avalanche risk for the "winter road", and three times higher at the "winter road". Nevertheless, the computed individual fatality risk of $1.16 \times 10^{-4}$ per year was above the risk of $10^{-5}$ to $10^{-6}$ fatalities per year, as indicated by Wilhelm (1999) as an upper boundary for the acceptable risk for road users. Merz et al. (1995) proposed an approach for the determination of threshold values regarding individual fatality risks based on the theory of voluntary risk acceptance and of possibilities to personally control the risk. According to this method, the computed risk for the Sulden road was within the accepted threshold value, if a marginal pos- sibility for self-determination for the road users is assumed. The risk was above the threshold level for the accepted risk, if the avalanche risk on roads is considered to be an involuntary risk. These findings lend support to the assumption that the individual fatality risk on the Sulden road due to snow avalanches is in the transition between acceptable and unacceptable risk. In this transition area, an efficient risk reduction can be achieved by temporary road closures. In contrast to the avalanche path no. 84068 ("Unterthurn"), the vulnerable "Marlt" debris cone road segment could be by-passed on the "winter road". Thus, temporary closures of the whole road may not be avoidable. A protection of the road segment threatened by the "Unterthurn" avalanche constructing a gallery would reduce a considerable part of the collective fatality risk due to snow avalanches, resulting in a substantial and permanent risk reduction. As outlined in the introduction section, the effectiveness of the temporary and permanent measures of risk reduction depends on the considered 
timeframe. Unless the "Unterthurn" avalanche gallery will be built, today's coping strategy for risk reduction has to be continued, therefore the road has to be temporarily closed.

For managing risks by temporary road closures, information on the short-term variability of risk is needed. This information can be provided using a short-term avalanche risk simulation. As presented in Fig. 4, the diurnal fatality risk can be estimated based on the actual environmental conditions and the effective damage potential in the endangered road section by means of a modified risk equation. If the resulting risk value exceeds a defined value, for example the average fatality risk due to road accidents, measures to reduce the risk should be implemented. The computed risk values showed a high short-term temporal variability. During similar avalanche hazard situations (avalanche hazard level 4) in the beginning of November 2003 and at the end of November 2003, the computed fatality risk varied due to a variable traffic density. On the other hand, risk peaks were computed at lower hazard level due to higher traffic density during holidays. On 1 November 2003, a fatality risk of $2.5 \times 10^{-3}$ per day was determined as a result of a traffic density of 320 cars per day. In contrast, on 31 December 2003, a fatality risk of $1.6 \times 10^{-2}$ per day was calculated from a traffic density of 1574 cars per day. This provides evidence for the importance of the consideration of the temporal variability of the damage potential for risk simulations on road networks. These results seem consistent with findings presented by Keiler et al. (2005) in the context of alpine settlements.

The validation regarding the short-term risk situation using data from the winter season of 2003/2004 suggested a reliability of the model, since the reported road closures were reproduced correctly. However, the statistical spread in the calculated risk values had shown a considerably range. Furthermore, the assumed dependence of the risk calculation on the sum of precipitation within three days is a simplified model. In addition, the statistical deduction of fracture probability and spatial occurrence probabilities of avalanches from the data used is connected to significant uncertainties (Zischg and Stötter, 2004).

Further research is needed particularly regarding parameters for the determination of the release probability of avalanches, as for instance presented in McClung and Schaerer (1993) and Schweizer (1999). The described method could be expanded by including additional components such as models for a computer-aided assessment of snow pack stability (e.g. Lehning et al., 1999), snow drift, or numerical avalanche forecasting (e.g. Brabec, 2001).

Nevertheless, the approach may contribute as a conceptual step towards a risk-based decision-making in risk management.

Acknowledgements. The authors thank M. Munari, C. Oberschmied, C. Mutinelli, H. Stuefer (Avalanche Warning Service, Autonomous Province of Bozen-South Tyrol, Italy) for providing the data and two anonymous reviewers for their insightful comments on the earlier draft of this paper.
Edited by: T. Glade

Reviewed by: two referees

\section{References}

Autonome Provinz Bozen-Südtirol/ASTAT: Verkehrsstatistik in Südtirol 2001, Bozen, 2002.

Autonome Provinz Bozen-Südtirol/ASTAT: Statistisches Jahrbuch für Südtirol 2003, Bozen, 2003.

Autonome Provinz Bozen-Südtirol/ASTAT: Online Verkehrsdatenbank, www.provinz.bz.it/astat/daten_online/default.htm, 2004.

Autonome Provinz Bozen-Südtirol/Lawinenwarndienst: Schlüssel für Meteonivometrische Beobachtungen an Schneemessfeldern, Bozen, 1983.

Autonome Provinz Bozen-Südtirol/Lawinenwarndienst: Kodex für Wetter und Schnee Beobachtungen, Bozen, 1997.

Autonome Provinz Bozen-Südtirol/Lawinenwarndienst: Lawinenkataster, Bozen, 2003.

Borter, P.: Risikoanalyse bei gravitativen Naturgefahren, edited by Bundesamt für Umwelt, Wald und Landschaft, Bern, 1999.

Brabec, B.: Computergestützte regionale Lawinenprognose, Diss. ETH/SLF No. 14232, ETH Zürich, Zürich, 2001.

Bründl, M., Etter, H.-J., Steiniger, M., Klingler, C., Rhyner, J., and Ammann, W.: IFKIS - a basis for managing avalanche risk in settlements and on roads in Switzerland, Nat. Haz. Earth Sys. Sci., 4, 257-262, 2004,

SRef-ID: 1684-9981/nhess/2004-4-257.

Fuchs, S., Bründl, M., and Stötter, J.: Development of avalanche risk between 1950 and 2000 in the municipality of Davos, Switzerland, Nat. Haz. Earth Sys. Sci., 4, 263-275, 2004, SRef-ID: 1684-9981/nhess/2004-4-263.

Fuchs, S. and Bründl, M.: Damage potential and losses resulting from snow avalanches in settlements of the canton of Grisons, Switzerland, Nat. Haz., 34, 53-69, 2005.

Hurton, J.: Sulden, Geschichte, Land, Leute und Berge, Bozen, 1991.

Keiler, M.: Development of the damage potential resulting from avalanche risk in the period 1950-2000, case study Galtür, Nat. Haz. Earth Sys. Sci., 4, 249-256, 2004, SRef-ID: 1684-9981/nhess/2004-4-249.

Keiler, M., Zischg, A., Fuchs, S., Hama, M., and Stötter, J.: Avalanche related damage potential - changes of persons and mobile values since the mid-twentieth century, Nat. Haz. Earth Sys. Sci., 5, 49-58, 2005,

\section{SRef-ID: 1684-9981/nhess/2005-5-49.}

Lehning, M., Bartelt, P., Brown, B., Russi, T., Stockli, U., and Zimmerli, M.: SNOWPACK model calculations for avalanche warning based upon a new network of weather and snow stations, Cold Reg. Sc., 30, 145-157, 1999.

Margreth, S., Stoffel, L., and Wilhelm, C.: Winter opening of high alpine pass roads - analysis and case studies from the Swiss Alps, Cold Reg. Sc. 37, 467-482, 2003.

Martinelli, M.: Schede di rivelamento sul terreno per la realizzazione della carta di localizzazione probabile delle valanghe, edited by: Autonome Provinz Bozen-Südtirol/Lawinenwarndienst, Lawinengefahrenkarte der Gemeinde Stilfs, Bozen, 1993.

McClung, D. M. and Schaerer, P. A.: The avalanche handbook, Seattle, 1993.

Merz, H., Schneider, T., and Bohnenblust, H.: Bewertung von technischen Risiken, Zürich, 1995. 
Schweizer, J.: Review of dry snow slab avalanche release, Cold Reg. Sc., 30, 43-57, 1999.

UN/ISDR: Living with Risk - A global review of disaster reduction initiatives, 2004 Version 1, Geneva, 2004.

Varnes, D.: Landslide hazard zonation: A review of principles and practice, Paris, 1984.

Wilhelm, C.: Wirtschaftlichkeit im Lawinenschutz, Eidgenössisches Institut für Schnee- und Lawinenforschung, Mitt. 54, Davos, 1997.

Wilhelm, C.: Kosten-Wirksamkeit von Lawinenschutzmassnahmen an Verkehrsachsen, edited by: Bundesamt für Umwelt, Wald und Landschaft, Praxishilfe, Bern, 1999.
Zischg, A.; Fuchs, S., and Stötter, J.: Uncertainties and fuzziness in analysing risk related to natural hazards - A case study in the Ortles Alps, South Tyrol, Italy, edited by: Brebbia, C., Risk Analysis IV, Management Information Systems 9, Southampton, 523-532, 2004.

Zischg, A. and Stötter, J.: Objektorientierte Betrachtung des Lawinenrisikos, Proc. Intern. Symp. Interpraevent - Riva del Garda, May 24-27, VI/217-VI/228, 2004. 